\title{
La función de los apetitos en la teoría del conocimiento sensitivo de Tomás de Aquino
}

\author{
(4) Fernando Gabriel Hernández \\ CONICET, Argentina \\ ORCID: 0000-0002-3954-0536
}

Recibido el o7 de marzo de 2020; aceptado el os de mayo de 2020.

\begin{abstract}
Resumen
Existe un principio en el pensamiento de Tomás de Aquino que sostiene que todo acto cognoscitivo es intencional. Este principio resulta problemático en el ámbito del conocimiento sensitivo porque contrasta con la idea de que los sentidos son totalmente pasivos y los objetos sensibles son causa suficiente de la percepción. La sinergia de estas tesis genera, al menos, dos conflictos: 1) entre la pasividad de los sentidos y su acción de dirigirse a los objetos; 2) entre la necesidad de la direccionalidad para conocer y la suficiencia de los objetos sensibles para causar la percepción. La aparente inconsistencia en la que caería el Aquinate puede resolverse analizando el rol que cumplen los apetitos intelectual, sensitivo y natural en su teoría del conocimiento sensitivo.
\end{abstract}

PALABRAS CLAVE: TOMÁS DE AQUINO, INTENCIONALIDAD, CONOCIMIENTO SENSITIVO, APETITOS, INTENCIÓN.

\section{The role of appetites in Thomas Aquinas's theory of sensitive knowledge}

\begin{abstract}
There is a principle in the thinking of Thomas Aquinas that maintains that every cognitive act is intentional. This principle is problematic in the field of sensitive knowledge because it contrasts with the idea that the senses are totally passive and that sensitive objects are the sufficient cause of perception. The synergy of these theses generates two kinds of conflicts: 1 ) between the passivity of the senses and their act of addressing objects; 2) between the need for directionality to knowledge and the sufficiency of sensitive objects to cause perception. The apparent inconsistency in which the Aquinate would fall can be resolved by analysing the role that corresponds to intellectual, sensitive and natural appetites in his theory of sensitive knowledge.
\end{abstract}




\section{Introducción}

De acuerdo con Tomás de Aquino, todo conocimiento es intencional ya que el sujeto se dirige hacia el objeto en el acto cognoscitivo. ${ }^{1}$ La percepción no es una excepción a esta regla y por eso el Aquinate sostiene que los sentidos se dirigen o se convierten a sus objetos propios en el acto perceptivo (cf. De veritate, q. 10, a. 2, ad 7). A pesar de lo plausible que pueda resultar dicha tesis para un autor contemporáneo, la intencionalidad en el ámbito del conocimiento sensitivo parece generar ciertos inconvenientes en la teoría del filósofo escolástico. En efecto, esta acción de dirigirse a los objetos percibidos contrasta con la pasividad característica que Tomás les atribuye a los sentidos externos en todo su corpus.

Pero eso no es todo, como veremos con mayor detalle a lo largo de este trabajo, la acción de dirigirse a los objetos es producto de lo que el Aquinate denomina intentio. Como hemos dicho, todo conocimiento es intencional y, por lo tanto, todo acto cognoscitivo requiere de la presencia de la intención sin la cual no puede darse. Los sentidos externos cumplen efectivamente con este requisito y esto genera ciertos problemas en relación a las condiciones necesarias y suficientes del acto perceptivo.

Tomás de Aquino señala que percibir no es más que padecer y que los objetos sensibles son causa suficiente de la percepción (cf. Quodlibet VIII, q. 2, a. 1, co.). Ahora bien, si la intención es necesaria para el acto perceptivo, se seguiría que los objetos son solo una causa necesaria para el conocimiento sensitivo. Estos dos puntos parecerían señalar que la tesis de la intencionalidad del conocimiento, que el Aquinate toma de Agustín de Hipona, es incompatible con la teoría de la percepción de cuño aristotélico.

El objetivo del presente trabajo consiste en mostrar que en realidad ambas tesis no son incompatibles como puede parecer a simple vista. Mostraremos que el Aquinate era consciente de los problemas que podrían surgir al querer sintetizar estas teorías y por eso les otorga un papel importante a todas las facultades apetitivas a la hora de explicar el acto perceptivo. Para mostrar de qué manera Tomás de Aquino logra introducir una perspectiva intencionalista en su teoría del conocimiento sensitivo dividiremos el trabajo en dos grandes secciones.

En la primera sección se presentarán los pasajes que parecen fundamentar la idea de que ambas tesis, a saber, la intencionalidad del conocimiento y la pasividad de los sentidos, son incompatibles. Luego se demostrará que los sentidos no son activos a pesar de que realmente se dirigen hacia sus objetos. Esto se debe a que la intentio por la cual tienden a tales objetos no es acto de los sentidos ni de ninguna facultad cognoscitiva. Además, utilizaremos este punto para estudiar el rol que cumple la voluntad en todo acto cognoscitivo.

En la segunda sección se argumentará que los objetos sensibles son causa suficiente de la percepción incluso cuando la intención es condición necesaria para la misma. En ese lugar se analizarán las diferencias que existen entre la intencionalidad del intelecto y la intencionalidad del sentido a fin de mostrar la complejidad en este último, ya que en ella participan múltiples actores. Para lograr este punto resultará fundamental mostrar de qué manera el apetito sensible y el apetito natural de las facultades sensitivas cumplen un papel importante en el origen de todo acto perceptivo. 


\title{
2. Sentidos externos ¿pasivos o activos?
}

Para Tomás de Aquino, la percepción puede ser explicada apelando a nociones causales ya que los objetos actúan como agentes y los órganos sensorios como pacientes del acto perceptivo. En relación a este punto, en los Quodlibet VIII se pregunta si el alma recibe de los objetos externos las especies a partir de las cuales conoce las cosas que están fuera de ella. Es decir, se trata de saber si los objetos son causa del conocimiento y, de ser así, se intenta establecer qué tipo de causa son. El Aquinate dirá que los objetos externos son efectivamente quienes originan las especies a partir de las cuales se conoce y la explicación de este tema es la ocasión que le permite a Tomás establecer una clasificación entre los diferentes tipos de agentes y pacientes:

\begin{abstract}
[1.1] Est enim quoddam agens quod de se sufficiens est ad inducendum formam suam in patiens, sicut ignis de se sufficit ad calefaciendum. [1.2] Quoddam vero agens est quod non sufficit de se ad inducendum formam suam in patiens, nisi superveniat aliud agens; sicut calor ignis non sufficit ad complendum actionem nutritionis nisi per virtutem animae nutritivae: unde virtus animae nutritivae est principaliter agens, calor vero igneus instrumentaliter. Similiter etiam est diversitas ex parte patientium. [2.1] Quoddam enim est patiens quod in nullo cooperatur agenti; sicut lapis cum sursum proiicitur, vel lignum cum ex eo fit scamnum. [2.2] Quoddam vero patiens est quod cooperatur agenti; sicut lapis cum deorsum proiicitur, et corpus hominis cum sanatur per artem (Quodlibet VIII, q. 2, a. 1, co.).

En efecto, existe [1.1] un agente que él mismo es suficiente para inducir su forma en el paciente, como el fuego es él mismo suficiente para calentar. Hay, sin embargo, [1.2] algún agente que él mismo no es suficiente para inducir su forma en el paciente, a no ser que sobrevenga otro agente, como el calor del fuego no es suficiente para completar la acción de nutrir si no fuera por la virtud del alma nutritiva. De donde la virtud del alma nutritiva es el agente principal y el calor del fuego es el agente instrumental. De la misma manera, hay una diversidad por parte del paciente. En efecto, existe [2.1] algún paciente que no coopera en nada con el agente, como la piedra cuando es lanzada hacia arriba o la madera cuando a partir de ella se hace una silla. Pero hay [2.2] algún paciente que sí coopera con el agente, como la piedra cuando es lanzada hacia abajo y el cuerpo del hombre cuando es sanado por la medicina (Quodlibet VIII, q. 2, a. 1, co.). ${ }^{2}$
\end{abstract}

Esta clasificación es útil para saber de qué manera son recibidas las especies en las diferentes potencias cognoscitivas, esto es, en los sentidos externos, la imaginación y el intelecto. Con respecto al intelecto Tomás afirma que el agente pertenece al segundo tipo mencionado y el paciente también es de la segunda clase. Esto es así porque las imágenes sensibles (phantasmata) de la imaginación no pueden mover por sí mismas al entendimiento posible [1.2] puesto que son inteligibles en potencia. Por este motivo se necesita la colaboración del entendimiento agente [2.2] para que, iluminándolos, los haga inteligibles en acto.

En la imaginación, por otra parte, el agente es del primer tipo y el paciente es del segundo tipo. Esto es, los objetos son agentes suficientes [1.1] para el acto imaginativo pero, a diferencia de los sentidos externos, la imaginación tiene la capacidad de manipular [2.2] las especies recibidas para formar nuevas imágenes. El ejemplo típico es el de unir las especies de oro y montaña para formar la imagen de una montaña de oro. Por último, en relación a los sentidos, el Aquinate afirma que los objetos externos son por sí mismos agentes suficientes [1.1] puesto que los sentidos se comportan como pacientes que no colaboran en nada [2.1].

2 La traducción de los pasajes de los Quodlibet, el Comentario a las Sentencias y De malo son del autor, mientras que para las demás obras se han utilizados las traducciones que se detallan en las referencias, haciendo las correcciones que he considerado pertinentes. 
Res quae sunt extra animam tripliciter se habent ad diversas animae potentias. Ad sensus enim extenorem se habent sicut agentia sufficientia, quibus patientia non cooperantur, sed recipiunt tantum. Quod autem color per se non possit movere visum nisi lux superveniat, non est contra hoc quod dictum est; quia tam color quam lux, inter esa quae sunt extra animam, computantur. Sensus autem exteriores suscipiunt tantum a rebus per modum patiendi, sine hoc quod aliquid cooperentur ad sui formationem (Quodlibet VIII, q. 2, a. 1, co.).

Las cosas que están fuera del alma se comportan de tres maneras con las diversas potencias del alma. En efecto, respecto a los sentidos externos se comportan como agentes suficientes, porque los pacientes no cooperan, sino que solo reciben. El hecho de que el color no pueda por sí mismo mover la visión si no le sobreviene la luz no es contrario a lo que se dijo aquí porque tanto el color como la luz se cuentan entre aquellas cosas que están fuera del alma. Los sentidos externos solo son afectados por el modo del padecer por las cosas, sin que cooperen en algo para su formación (Quodlibet VIII, q. 2, a. 1, co.).

La afirmación de que los sentidos son totalmente pasivos y "se limitan a recibir" no debe sorprender puesto que es una tesis que se remonta hasta Aristóteles. Sin embargo, el problema surge cuando observamos que en ciertos lugares Tomás de Aquino parece atribuirle algún tipo de actividad a los sentidos externos. Esta actividad se relaciona con la intencionalidad que está involucrada en todo acto cognoscitivo.

Hoc enim in omnibus animae potentiis invenimus, quod quando una potentia in suo actu intenditur, alia vel debilitatur in suo actu, vel ex toto abstrahitur; sicut patet in illo in quo operatio visus fortissime intenditur, quod auditus eius non percipit ea quae dicuntur, nisi forte sua vehementia ad se trahant sensum audientis. Cuius ratio est, quia ad actum alicuius cognoscitivae potentiae requiritur intentio, ut probat Augustinus in Lib. de Trinit. (De veritate, q. 13 , a. 3 , co.).

En efecto, encontramos en todas las potencias del alma que cuando una potencia tiende a su acto, otra o se debilita en su acto o se abstrae por completo, como se observa cuando la vista tiende a su operación de manera fuertísima, ocurre que el oído no percibe lo que se le dice, a no ser que su vehemencia sea tan fuerte que arrastre el sentido del que escucha. Por esta razón es que se requiere la intención para el acto de alguna potencia cognoscitiva, como prueba Agustín en el libro Sobre la Trinidad (De veritate, q. 13, a. 3, co.).

En el caso del pasaje citado, el oído no percibe lo que se está diciendo porque le falta la intención necesaria para llevar al acto su operación puesto que la misma se encuentra concentrada en otro sentido externo, a saber, la vista. En De veritate, $\mathrm{q}$. 10, el Aquinate destaca el rol activo que cumplen todas las potencias cognoscitivas y afirma que: "nulla potentia potest aliquid cognoscere nisi convertendo se ad obiectum suum, ut visus nihil cognoscit nisi convertendo se ad colorem" [ninguna potencia puede conocer algo más que convirtiéndose a su objeto, como por ejemplo la vista no conoce nada más que convirtiéndose al color] (De veritate, q. 10, a. 2, ad 7). No es menor que el ejemplo que utiliza sea nuevamente el de un sentido externo. Por último, en la Summa contra gentiles afirma lo siguiente:

Vis cognoscitiva non cognoscit aliquid actu nisi adsit intentio: unde et phantasmata in organo conservata interdum non actu imaginamur, quia intentio non fertur ad ea (SCG I, c. 55, n. 4)

La potencia cognoscitiva nada conoce en acto a no ser que esté presente la intención; de donde algunas veces no imaginamos en acto las imágenes conservadas en el órgano, debido a que la intención no se dirige a ellas (SCG I, c. 55, n. 4). 
En este caso el ejemplo se refiere a la actividad de la imaginación, pero lo que tienen en común todos estos pasajes es que afirman de manera general que toda potencia cognoscitiva necesita de la intentio por medio de la cual el sujeto se dirige hacia el objeto. De acuerdo con lo dicho puede afirmarse que todas las facultades cognoscitivas, incluyendo a los sentidos externos, necesitan de la intención para poder llevar al acto su operación.

La clasificación realizada en los Quodlibet según la cual los sentidos externos son pacientes que no colaboran en nada a la acción del agente es coherente con la definición aristotélica de los sentidos que el mismo Tomás de Aquino acepta: "la facultad capaz de recibir las formas sensibles sin la materia al modo en que la cera recibe la marca del anillo sin el hierro ni el oro" (Aristóteles, De anima 424a 19: 201). De hecho, es un tópico frecuente asumir que en su teoría de la percepción los sentidos externos son absolutamente pasivos (cf. Carcedo, 1992: 205-209; Beuchot, 2008: 14-31).

Por otro lado, en varios pasajes de su corpus afirma que proviene de Agustín de Hipona la tesis que sostiene la necesidad de la intentio para llevar al acto las operaciones de las potencias cognoscitivas. El Hiponense afirma que para que haya conocimiento de algún tipo se necesita la participación de tres actores: el sujeto, el objeto y la intención. La función de la intención sería la de establecer una conexión entre el sujeto y el objeto (cf. Agustín, De trinitate XI.2.2-5). Tomás de Aquino, como buen teólogo escolástico, no puede contradecir ni desentenderse de la afirmación de semejante autoridad eclesiástica y es por eso que debe tener en cuenta sus palabras. Lo que debemos saber es si el querer compatibilizar las posiciones de Aristóteles y Agustín lo llevó a desarrollar una teoría de la percepción inconsistente.

En efecto, pueden señalarse al menos dos problemas: 1) el Aquinate afirma que los objetos sensibles son causa suficiente de la percepción; sin embargo, hemos visto que en varios lugares sostiene que también es necesaria la intención sin la cual no puede producirse el acto cognoscitivo. En la próxima sección trataremos la cuestión acerca de la suficiencia o insuficiencia de los objetos para causar la percepción. 2) El otro problema se encuentra en la afirmación de que los sentidos son totalmente pasivos y que, a la vez, deben dirigirse hacia sus objetos para que se produzca el acto cognoscitivo. La direccionalidad que se observa en todo tipo de conocimiento parece ser un aspecto activo que se contrapone a la pasividad propia de los sentidos externos.

Para resolver el problema señalado en el segundo punto se debe advertir que la intención no es un acto de los sentidos. La direccionalidad del conocimiento, tanto a nivel intelectual como sensitivo, es producto de la intentio que "sicut ipsum nomen sonat, significat in aliquid tendere" [como su mismo nombre da a entender, significa tender hacia algo] (ST I-II, q. 12, a. 1, co.). Ahora bien, para el Aquinate "manifestum est quod intentio proprie est actus voluntatis" [es manifiesto que la intención es un acto propio de la voluntad] (ST I-II, q. 12, a. 1, co.) y no de alguna facultad cognoscitiva. Es por eso que resulta lícito afirmar que para Tomás de Aquino hay una verdadera intencionalidad en el acto cognoscitivo, pero esta direccionalidad es acto de la voluntad porque es ella la que "tiende hacia algo".

Esta conclusión muestra que es erróneo pensar que la direccionalidad del conocimiento está dada por la existencia intencional (esse intentionale) que poseen las formas que se encuentran en los entes que sienten o piensan. De hecho, una parte importante de los escritos sobre la intencionalidad en la gnoseología del doctor angélico sigue esta línea interpretativa y lo postulan tanto en su teoría del conocimiento sensitivo como intelectual. ${ }^{3}$

3 Entre los autores que identifican la existencia intencional con la direccionalidad del conocimiento se encuentran Brower y Brower-Toland, 2008; Pasnau, 1997; Geach, 1954; Davies, 1992; Haldane, 1993; Panaccio, 1997; y Perler, 2004. 
[P]ara Tomas de Aquino también en el conocimiento sensible tiene lugar la intencionalidad cognoscitiva, es decir, esa peculiar situación por la que se entiende que lo conocido es poseído por el cognoscente de una manera diferente a la física y que esta posesión remite a la cosa misma, sin otra mediación que la de la posesión formal (Moya, 1999: 88). ${ }^{4}$

Existen investigaciones que muestran de manera plausible que el esse intentionale no implica direccionalidad, ${ }^{5}$ siendo necesario distinguir entre el término intentio aplicado a la forma que tiene una existencia intencional y la intentio que es acto de la voluntad. La primera intención mencionada se refiere al mensaje que se encuentra tanto en seres carentes de conocimiento como en los seres capaces de conocer. En cambio, la intención de la voluntad hace referencia a la direccionalidad o referencialidad de algunos actos volitivos entre los cuales se incluyen los actos de conocimiento.

\footnotetext{
"Intentio" was the word selected by the Latin translators of Avicenna to translate the Arabic ma'na; the fundamental Arabic verb involved here, 'ana, they translated velle dicere (cf. French vouloir dire), i.e., "to mean" or "to intend to say". Thus, "intention" is best rendered by such English words as "meaning" or "notion". In our context of sensibles and sense, it means the message sent from the sensible to the sense. It is misleading to put emphasis on the notion of tendency in the etymology of "intention" (Dewan, 1980: 239).
}

El hecho de que la intencionalidad del conocimiento dependa de la voluntad y no de las formas que tiene un esse intentionale permite explicar de manera filosófica ciertas cuestiones que atañen a la teología como, por ejemplo, el que ninguna criatura intelectual pueda conocer lo que otro ente está pensando, ya que esto es algo privativo de Dios. En este sentido es oportuno analizar el desarrollo que el Aquinate realiza sobre una cuestión que puede parecer ajena a la filosofía, a saber, si los ángeles pueden conocer nuestros pensamientos. Este tema se encuentra en De malo, q. 16, a. 8 y en De veritate, q. 8 , a. $13 .^{6}$

A pesar de ser un tema claramente teológico, estos textos son relevantes por varios motivos: 1) son los únicos lugares, al menos hasta donde tenemos conocimiento, en los que se menciona la función que cumple el apetito sensitivo en la percepción; 2) revelan ciertas posiciones filosóficas que son asumidas por Tomás como, por ejemplo, que el ser humano es capaz de dirigir su atención hacia un objeto voluntariamente y considerarlo desde diferentes aspectos y con distinta intensidad; 3) muestran que la representación mental es importante, pero también lo es el acto por el cual uno atiende a estas representaciones; 4) evidencian que la cognición no consiste únicamente en un cierto estatus metafísico, esto es, poseer formas con un esse intentionale, sino que también hay un aspecto psicológico del ser humano que tiene relevancia.

En esta discusión el Aquinate utiliza varios términos para referirse a los pensamientos del ser humano, algunos de ellos son: cogitationes cordis, cogitationes internae e id quod est in cogitatione vel voluntate. Todas estas expresiones hacen referencia a pensamientos que no son expresados y que permanecen en el fuero interno de la conciencia del individuo. Lo que se intenta saber es si los ángeles pueden tener acceso a los pensamientos más privados del ser humano.

\footnotetext{
4 El subrayado es mío.

5 Véase Sorabji, 1991; Caston, 2005; Klima, 2013; Moser, 2011; y Sanguineti, 2011.

6 Si bien estos pasajes son paralelos, debe aclararse que en De malo Tomás se pregunta si los demonios (ángeles caídos) pueden conocer los pensamientos del corazón, mientras que en De veritate se pregunta si los ángeles en general pueden conocer lo que está oculto en el corazón. Considero que esta es solo una diferencia secundaria que se explica por el contexto donde se encuentran los respectivos artículos pero que no hace al caso el saber si los ángeles son "buenos" o "malos" al momento de hablar sobre su capacidad cognoscitiva. Por este motivo trato la cuestión como si en ambas obras estuviera refiriéndose a la naturaleza angélica sin más.
} 
En el responsio de De malo, q. 16, a. 8 se distinguen dos maneras en las que alguien puede conocer lo que otro está pensando: 1) de una manera, según cómo los pensamientos son vistos en sí mismos y esta es la forma en la que una persona conoce sus propios pensamientos; 2) de otra manera, de acuerdo a cómo esos pensamientos son vistos por signos corporales. Con respecto a esta última manera, en De veritate, q. 8 , a. 13 Tomás vuelve a hacer una nueva distinción en la que alguien puede "leer" los pensamientos de otra persona:

[2.1] Uno modo inquantum ex cogitatione actuali resultat aliquis motus in corpore, dum aliquis gaudio vel tristitia afficitur ex his quae cogitat, et sic cor quodammodo movetur. Per hunc enim modum etiam medici quandoque possunt passionem cordis cognoscere. [2.2] Alio modo inquantum ex actuali cogitatione aliquis meretur vel demeretur; et sic mutatur quodammodo status agentis vel cogitantis in bonum vel in malum. Et hanc dispositionum mutationem Angeli cognoscunt (De veritate, q. 8, a. 13, co.).

[2.1] De un modo, en cuanto del pensamiento actual resulta un movimiento en el cuerpo mientras alguien es afectado por el gozo o la tristeza por las cosas que piensa, y así el corazón en cierta manera se mueve. En efecto, por este modo los médicos en ocasiones pueden conocer la pasión del corazón. [2.2] De otro modo en cuanto a partir de un pensamiento actual alguien merece o desmerece, y así en cierto modo el estado del que obra o del que piensa se transforma en bueno o en malo. Los ángeles conocen esta mutación de las disposiciones (De veritate, q. 8, a. 13, co.).

El primer tipo de movimiento o mutación, que también es mencionado en De malo, es corporal. Uno puede saber que alguien está pensando en cosas tristes, por ejemplo, porque observa lágrimas, llantos o algún gesto facial que manifiestan ese tipo de pensamientos. Tomás de Aquino sostiene que los ángeles pueden tener aún más certeza que un ser humano debido a que ellos, además de estos movimientos externos, pueden conocer los movimientos del corazón. Hay que tener en cuenta que para el Aquinate toda pasión está constituida por un elemento formal y otro material. ${ }^{7} \mathrm{El}$ elemento formal de la ira, por ejemplo, es el deseo de venganza y el elemento material es la ascensión de la sangre junto al corazón. ${ }^{8}$ El elemento material no es siempre visto de manera directa por nosotros, pero sí por los ángeles.

El segundo tipo de mutación mencionado es mucho más complejo de entender. El Aquinate habla de status agentis y de una dispositionum mutationem en relación al merecimiento o desmerecimiento, pero no desarrolla el tema. Una pequeña mención es encontrada en la respuesta a la sexta objeción donde se dice que Orígenes sostuvo que todo pensamiento deja una señal o signo en el alma. El Doctor Angélico acepta esta postura y se remite al cuerpo del artículo para afirmar que el conocimiento que se tiene de esas señales no es directo.

A manera de hipótesis, 9 se puede decir que los pensamientos a partir de los cuales alguien merece o desmerece serían los pensamientos que hacen que alguien adquiera o pierda la gracia santificante. Para Tomás de Aquino nadie puede merecer la vida eterna sin la gracia (cf. ST I-II, q. 109, a. 5) y la misma puede ser ganada o perdida de acuerdo a los pensamientos que uno tenga. De ahí se sigue que alguien puede "merecer" o "desmerecer" la salvación como consecuencia de sus pensamientos.

7 Para un desarrollo más completo de la naturaleza de la pasión véase González Vidal, 2008: 17-21.

8 Tomás, ST I, q. 20, a. 1, ad 2: "in passionibus sensitivi appetitus, est considerare aliquid quasi materiale, scilicet corporalem transmutationem; et aliquid quasi formale, quod est ex parte appetitus. Sicut in ira, ut dicitur in I de anima, materiale est accensio sanguinis circa cor, vel aliquid huiusmodi; formale vero, appetitus vindictae".

9 Se propone una hipótesis porque considero que el tema merece algún tipo de explicación pero no lo desarrollo porque excede al tema principal de este trabajo. 
Además, el Aquinate afirma que nadie puede saber con certeza si posee la gracia santificante, pero es posible realizar alguna conjetura sobre su posesión a partir de ciertos indicios (cf. ST I-II, q. 112, a. 5; De veritate, q. 10, a. 10). La gracia es una disposición (véase ST I-II, q. 110, a. 3, ad 3) y por eso cuando se adquiere o pierde es probable que ocurra una "mutación de la disposición" (dispositionum mutationem), como se lee en el pasaje citado. Esta mutación produciría un cambio en el "estatus del que obra" (status agentis), puesto que pasa de merecer la salvación a desmerecerla. Esta sería la otra mutación que puede ser conocida por las naturalezas angélicas.

Ahora bien, estas dos maneras de conocer los pensamientos de los seres humanos son consideradas como un conocimiento indirecto, accidental y general por Tomás de Aquino, puesto que parten de ciertos signos corporales. Es el primer tipo de conocimiento mencionado, aquel en el que se conocen los pensamientos en sí mismos, el que realmente nos interesa. Con respecto a este tipo de conocimiento el Angélico dirá que ningún ente creado puede conocer de manera directa los pensamientos de otro ente y esto se debe a que los mismos dependen de la voluntad, más específicamente, de la intentio de la voluntad.

Responsio. Dicendum, quod Angeli cogitationes cordium per se et directe intueri non possunt. Ad hoc enim quod mens aliquid actu cogitet, requiritur intentio voluntatis, qua mens convertatur actu ad speciem quam habet (De veritate, q. 8, a. 13, co.).

Respondo. Debe decirse que los ángeles no pueden observar directamente y por sí mismos los pensamientos de los corazones. En efecto, para que la mente piense algo en acto, se requiere la intención de la voluntad por la cual la mente se convierte en acto a la especie que posee (De veritate, q. 8, a. 13, co.).

Para el Aquinate los ángeles pueden conocer las especies inteligibles que están en nuestro entendimiento y esto se debe a que ellos no carecen de ninguna forma de los entes naturales. Ahora bien, poseer especies inteligibles no es equivalente a pensar, ya que se necesita que el ser humano haga uso de alguna de esas especies para que el acto cognoscitivo ocurra: "potest autem visus spiritualis Angeli [...] videre formas spirituales intellectus nostri; non tamen propter hoc vident qualiter eis utamur cogitando" [la visión espiritual del ángel [...] puede ver las formas espirituales de nuestro intelecto, sin embargo, no pueden ver cómo las usamos para pensar] (De malo, q. 16, a. 8, ad 2). Como señala Scarpelli Cory (2015) "uso" (uti) es un término técnico que hace referencia al acto de la voluntad de mover otras potencias del alma para que realicen su operación propia. ${ }^{10}$ En este caso la voluntad mueve al intelecto a elegir una de las especies inteligibles que posee y a partir de esta elección el sujeto piensa "acerca de" algo.

La imposibilidad de saber lo que alguien está pensando radica en que no se puede conocer la direccionalidad de su intención. Esta direccionalidad depende exclusivamente de la voluntad. Pero no se trata meramente de saber qué especie inteligible está usando, sino que también se tiene que saber a qué aspecto de la especie elegida está atendiendo. Por eso, aun suponiendo que un ángel sepa qué especie inteligible va a ser usada, no podrá saber con precisión sobre qué versa el pensamiento.

Ad secundum dicendum, quod ex una specie quam intellectus penes se habet, in diversas cogitationes prodit, sicut per speciem hominis varia de homine possumus cogitare. Unde etsi Angelus videat intellectum nostrum figurari secundum speciem hominis, non sequitur quod cogitationem cordis determinate cognoscat (De veritate, q. 8, a. 13, ad 2). 


\begin{abstract}
A lo segundo se debe decir que desde una sola especie que el intelecto tiene en sí mismo procede hacia diversos pensamientos, como por la especie del hombre podemos pensar diversas cosas sobre el hombre. De ahí que por más que el ángel vea que nuestro intelecto se configura según la especie del hombre, no se sigue que conozca de manera determinada el pensamiento del corazón (De veritate, q. 8, a. 13, ad 2).
\end{abstract}

Se observa con claridad en este pasaje que lo determinante del acto cognoscitivo no es la posesión de formas inteligibles, este es un requisito necesario pero no suficiente para el acto cognoscitivo. También es necesaria la intencionalidad, esto es, la direccionalidad hacia un objeto que es un acto de la voluntad, no del intelecto. Se debe tener en cuenta que el término intentio significa lo mismo que conversio: volverse hacia un objeto (cf. Pasnau, 1997: 135; Lane, 2013: 19). Y en este sentido tanto el intelecto como el sentido se dirigen o se convierten hacia sus objetos.

\footnotetext{
Ad septimum dicendum, quod nulla potentia potest aliquid cognoscere nisi convertendo se ad obiectum suum, ut visus nihil cognoscit nisi convertendo se ad colorem. Unde, cum phantasma hoc modo se habeat ad intellectum possibilem sicut sensibilia ad sensum, ut patet per philosophum in III de anima, quantumcumque aliquam speciem intelligibilem apud se intellectus habeat, nunquam tamen actu aliquid considerat secundum illam speciem, nisi convertendo se ad phantasma (De veritate, q. 10, a. 2, ad 7).
}

A lo séptimo debe decirse que ninguna potencia puede conocer algo a no ser que se convierta a su objeto, como la vista que nada conoce si no se convierte al color. De ahí que debido a que la imagen se comporta con el intelecto posible como las cosas sensibles con el sentido, como es manifiesto por el Filósofo en el libro III del De anima, por más que el intelecto tenga alguna especie inteligible consigo, nunca considera en acto según esa especie, a menos que se convierta a la imagen (De veritate, q. 10, a. 2, ad 7).

Como mencionamos anteriormente, pensar consiste en elegir y usar una de las especies inteligibles que se posee. Este "atender" a una determinada especie es obra de la intentio de la voluntad. En este pasaje se puede entrever que la posesión de la especie es un momento del acto cognoscitivo y otro momento consiste en la conversión al fantasma. Algo similar sucede con los sentidos, ya que ninguno de ellos percibe a menos que se convierta o dirija hacia su objeto propio. Por este motivo Tomás de Aquino afirma que la vista nada conoce si no se convierte hacia su objeto propio, que es el color.

A partir de lo dicho sería posible resolver el problema de la supuesta actividad de los sentidos. En efecto, puede sostenerse que los sentidos son absolutamente pasivos porque son movidos tanto por los objetos externos cuando los inmutan, como por la voluntad cuando los direcciona hacia sus objetos propios (cf. Pasnau, 1997: 138). La direccionalidad que es necesaria para el acto cognoscitivo no surge de los sentidos mismos por lo que nunca dejan de ser pasivos. De esta manera puede pensarse que el rol activo de los sentidos no es tal, en cuanto que son móviles y nunca motores.

Ahora bien, aunque se puede seguir sosteniendo que los sentidos externos son absolutamente pasivos, el problema persiste porque Tomás de Aquino afirma que los objetos externos son causa suficiente de la percepción. Si además de la inmutación por parte de los objetos es necesaria la intención de la voluntad, los objetos externos serían una causa necesaria pero no suficiente para llevar al acto la operación de los sentidos. Esto es, la percepción sería producto de la cooperación de dos causas por lo que sería errónea la clasificación dada en los Quodlibet. En la siguiente sección veremos de qué manera la intención puede estar presente y, sin embargo, los objetos sensibles pueden ser causa suficiente de la percepción. 


\title{
3. La participación de los apetitos en el conocimiento sensitivo
}

Hemos señalado que la intención no es acto de ninguna facultad cognoscitiva y, si bien Tomás de Aquino se la atribuye propiamente a la voluntad, lo cierto es que la intentio es acto de toda potencia apetitiva, por eso sostiene que "intentio non est actus cognoscitivae, sed appetitivae" [la intención no es un acto cognoscitivo, sino apetitivo] (In Sent. II, d. 38, q. 1, a. 3, co.). Ahora bien, para el Aquinate existen dos facultades apetitivas en los entes cognoscitivos: una facultad apetitiva intelectual, que es la voluntad, y una facultad apetitiva sensitiva:

\begin{abstract}
[I]ntentio est virtutis appetitivae actus: quae quidem est duplex. Una sensitiva, quae quidem est virtus organi corporei [...]. Alia autem est vis appetitiva intellectiva, scilicet voluntas: quae quia non habet organum corporale, non immutatur ex corporali immutatione, nisi dispositive (De malo, q. 16, a. 11, ad 3).
\end{abstract}

La intención es acto de la facultad apetitiva, que es doble: una sensitiva, que es la potencia de un órgano corporal [...]. Otra es una potencia apetitiva intelectual, a saber, la voluntad, que porque no tiene un órgano corporal, no es inmutada por la inmutación corporal, a no ser dispositivamente (De malo, q. 16, a. 11, ad 3).

La intentio de la parte intelectual siempre depende del sujeto y nunca puede ser violentada por otro ente, aunque sí puede ser movida por Dios. Como ningún objeto externo puede forzar esta intención, ningún ser puede conocer lo que está pensando otro ente puesto que es algo enteramente subjetivo, como hemos visto en la sección anterior. Además, gracias a la voluntad uno puede elegir qué especie inteligible considerar y sobre qué aspecto de esa misma especie pensar (cf. De malo, q. 16, a. 8).

La voluntad es una potencia apetitiva que puede mover tanto al intelecto como a los sentidos. Esto es importante porque para Tomás de Aquino nosotros tenemos la facultad de elegir qué objeto considerar y qué objeto ignorar, no solo en el plano intelectual, sino también con respecto a los sentidos y la imaginación. El tema de la voluntariedad de la percepción es mencionado en el tratamiento de la visión profética. Para el Aquinate la visión profética precisa de la enajenación de los sentidos y, explicando esto, afirma que existen dos causas de esta enajenación: una natural y otra anímica.

Sed haec abstractio dupliciter contingit: uno modo ex causa animali; alio modo ex causa naturali. A causa quidem naturali quando exteriores sensus stupescunt vel propter aegritudinem, vel propter vapores somni ad cerebrum ascendentes, ex quibus contingit organum tactus immobilitari. Ex causa vero animali, sicut quando homo ex nimia attentione ad intellectualia vel imaginabilia omnino a sensibus exterioribus abstrahitur (De veritate, q. 12 , a. 9 , co.).

Pero esta abstracción sucede de dos maneras: de un modo por una causa animal, de otro modo por una causa natural. Por causa natural cuando los sentidos exteriores se suspenden o bien por una enfermedad, o bien por los vapores del sueño que ascienden al cerebro, a partir de esto sucede que el órgano del tacto queda inmóvil. Por causa animal, como cuando el hombre por una excesiva atención a lo pensado o imaginado se abstrae por completo de los sentidos exteriores (De veritate, q. 12, a. 9, co.).

Esto es así porque la intentio no puede extenderse a cosas diversas, mucho menos cuando la misma es muy intensa (cf. ST I-II, q. 33, a. 3). Luego, si alguien voluntariamente se convierte a los objetos de la inteligencia o de la imaginación, es capaz de ignorar o de no atender (intentio) a los objetos sensibles externos. Lo mismo sucede cuando uno atiende con intensidad a un objeto externo en detrimento de otro. 


\begin{abstract}
Manifestum est enim quod quandocumque una potentia intenditur in suo actu, alia potentia vel impeditur vel totaliter avertitur a suo actu; sicut cum aliquis intentus est ad aliquem audiendum, non percipit hominem pertranseuntem (De malo, q. 3, a. 9, co.).

Es manifiesto que siempre que una potencia tiende a su acto, otra potencia o es impedida o es removida totalmente de su acto. Como cuando alguien está atento (intentus) para escuchar a alguien, no percibe a un hombre que pasa por allí (De malo, q. 3, a. 9, co.).
\end{abstract}

Todo esto es producto de la intentio de la voluntad porque el sujeto elige atender al sonido que está escuchando y la intensidad de esa atención produce que otro objeto sensible no sea percibido. Ahora bien, si la intención que se requiere para conocer fuera siempre de la parte intelectual, Tomás no podría responder al siguiente argumento que sostiene que los ángeles no pueden enseñar a los seres humanos.

Sed dicebat, quod Angeli nos docent quodammodo exterius, inquantum in nostram imaginationem imprimunt. - Sed contra, species imaginationi impressa ad imaginandum in actu non sufficit, nisi adsit intentio, ut patet per Augustinum in Lib. de Trinit. Sed intentionem non potest in nobis inducere Angelus: cum intentio sit voluntatis actus, in quam solus Deus imprimere potest. Ergo nec etiam imprimendo in imaginationem Angelus docere nos potest, cum, mediante imaginatione, non possimus doceri nisi actu aliquid imaginando (De veritate, q. 11, a. 3, arg. 2).

Pero se dijo que los ángeles nos enseñan de cierta manera exteriormente, en cuanto que influyen en nuestra imaginación. Pero en contra está que la especie impresa en la imaginación no es suficiente para imaginarla en acto a no ser que esté presente la intención, como consta por Agustín en el libro De Trinitate. Pero el ángel no puede inducir la intención en nosotros debido a que la intención es acto de voluntad, en la que solo Dios puede influir. Por lo tanto, un ángel ni siquiera actuando en la imaginación puede enseñarnos ya que no podemos ser enseñados mediante la imaginación a no ser que imaginemos algo en acto (De veritate, q. 11, a. 3, arg. 2).

El argumento es correcto. Para Tomás de Aquino la intención depende de la voluntad y la misma es accesible únicamente al propio sujeto y a Dios (cf. De veritate, q. 8 , a. 13, co.). Si para todo tipo de conocimiento se necesitara la intención, como el mismo Aquinate afirma, ningún ente podría enseñarnos algo porque siempre estaría en nuestras manos poder no atender a aquello que nos intenta presentar. Sin embargo, esto es cierto en el conocimiento intelectual, pero no lo es para el conocimiento sensitivo.

\footnotetext{
Ad secundum dicendum, quod quamvis intentio voluntatis cogi non possit, tamen intentio sensitivae partis cogi potest: sicut cum quis pungitur, necesse habet intendere ad laesionem; et ita est etiam de omnibus aliis virtutibus sensitivis, quae utuntur organo corporali; et talis intentio sufficit ad imaginationem (De veritate, q. 11, a. 3, ad 2).
}

Al segundo debe decirse que aunque la intención de la voluntad no pueda ser forzada, la intención de la parte sensitiva puede ser forzada. Así, cuando alguien se pincha, necesariamente tiene que atender (intendere) a la lesión. Y de este modo es para todas las otras facultades sensitivas, que usan de un órgano corporal, y tal intención es suficiente para imaginar (De veritate, q. 11, a. 3, ad 2).

La frase la "intención de la parte sensitiva" necesita una aclaración. Así como la intentio de la parte intelectual (perteneciente al apetito intelectual) mueve al intelecto a considerar su objeto, de la misma manera la intención de la parte sensitiva (perteneciente al apetito sensitivo) mueve a la imaginación y a los sentidos externos 
a considerar sus objetos. De esta manera, la "intención de la parte sensitiva" hace referencia al acto del apetito sensitivo que mueve a las potencias sensitivas, a saber, la imaginación y los sentidos externos.

Ad quartum dicendum, quod ad hoc quod homo actu consideret secundum species quae habitualiter in intellectu existunt, requiritur intentio voluntatis: nam habitus est quo quis agit cum voluerit, ut dicitur in III de anima; et similiter per intentionem appetitus sensitivi contingit quod actu animal imaginetur ea quae prius in memoria conservabantur (De malo, q. 16 a. 11, ad 4).

A lo cuarto debe decirse que para que un hombre considere en acto según las especies que existe en hábito en el intelecto, se requiere la intención de la voluntad, ya que el hábito es lo que alguien hace cuando quiere, como se dice en el libro III del De anima. Y de manera similar, por la intención del apetito sensitivo ocurre que el animal se imagine en acto lo que anteriormente se conservaba en la memoria (De malo, q. 16 a. 11, ad 4).

Tomás de Aquino afirma de manera directa que la intención del apetito sensitivo hace que el animal imagine algo en acto. En el pasaje anterior observamos que la intención de la parte sensitiva puede ser forzada en otras "facultades sensitivas que usan órganos corporales". Podemos pensar que los sentidos externos deben entrar en esta categoría por el hecho de que usan órganos corporales. De esta manera, como los ángeles pueden forzar la intención de la parte sensitiva son capaces de enseñar al ser humano llevando al acto a la imaginación y a los sentidos externos.

De hecho, en De malo, q. 16, a. 11 el Aquinate sostiene que los demonios pueden inmutar la facultad cognoscitiva sensitiva y de esa manera hacer que una persona sienta o se imagine lo que ellos deseen. Lo interesante de esta cuestión es que los sentidos externos son mencionados de manera explícita por Tomás de Aquino. Una objeción en contra de su postura sostiene que tal influencia no sería posible porque se necesitaría de la intención de la voluntad para que el sentido y la imaginación sean llevados al acto.

Sed dicendum, quod Daemon movet sensum ad imaginationem, non quidem imprimendo novas species, sed species praeexistentes in spiritibus sensitivis reducendo ad organum imaginationis vel sensus. - Sed contra, Augustinus dicit in XI de Trin., quod ad videndum quacumque visione exigitur intentio, quae coniungat speciem visibilem ipsi potentiae visivae. Intentio autem pertinet ad vim appetitivam, quam Daemon movere non potest, quia sic hominem cogeret ad peccandum, cum in appetitu consistat peccatum. Non ergo per hoc quod reducit formas ad organum sensus vel imaginationis, potest movere hominem ad hoc quod sentiat vel imaginetur (De malo, q. 16, a. 11, arg. 3).

Pero debe decirse que el Demonio mueve al sentido para imaginar, no imprimiendo especies nuevas, sino reduciendo las especies preexistentes en los espíritus sensibles al órgano de la imaginación o el sentido. Pero en contra está lo que Agustín dice en el libro XI del De Trinitate, que para ver por cualquier acto de visión se exige la intención, que conjuga la especie visible misma con la potencia visiva. Pero la intención pertenece a la potencia apetitiva, que el Demonio no puede mover, porque de otra manera puede llevar al hombre a pecar, en cuanto que consiente al pecado en el apetito. Por lo tanto, por esto reduce las formas al órgano del sentido o la imaginación, no puede mover al hombre para que sienta o imagine (De malo, q. 16, a. 11, arg. 3).

A partir de lo dicho anteriormente resulta evidente que la respuesta vendrá por parte de la intención del apetito sensitivo. 


\begin{abstract}
Ad tertium dicendum, quod intentio est virtutis appetitivae actus: quae quidem est duplex. Una sensitiva, quae quidem est virtus organi corporei; unde potest eius actus ab aliqua corporali transmutatione causari; sicut ex aliquo corporali apposito vel subtracto appetitus sensitivus movetur ad aliquid desiderandum vel fugiendum; et hoc modo Daemones possunt immutare appetitum sensitivum ad aliquid intendendum. Alia autem est vis appetitiva intellectiva, scilicet voluntas: quae quia non habet organum corporale, non immutatur ex corporali immutatione, nisi dispositive; effective autem mutari potest vel ab ipso homine, secundum quod voluntas movet seipsam, vel a Deo, qui interius operatur. Unde secundum hoc Daemones non possunt movere animam ad aliquid intendendum (De malo, q. 16, a. 11, ad 3).
\end{abstract}

A lo tercero debe decirse que la intención es acto de la facultad apetitiva, que es doble: una sensitiva, que es una potencia de un órgano corporal, de ahí que su acto puede ser causado por alguna transmutación corporal. Como a partir de presentarle o quitarle algo corporal el apetito sensitivo es movido a desear o evitar algo. Y de este modo los demonios pueden inmutar el apetito sensitivo para que tienda a algo. Otra es una potencia apetitiva intelectual, a saber, la voluntad, que porque no tiene un órgano corporal, no es inmutada por la inmutación corporal, a no ser dispositivamente. De manera eficiente el hombre puede ser movido o bien por el hombre mismo, en cuanto la voluntad se mueve a sí misma, o bien por Dios, que obra en el interior. Según esto los demonios no pueden mover al alma para que tienda a algo (De malo, q. 16, a. 11, ad 3).

La intención de la voluntad jamás puede ser forzada por un ente creado, pero sí puede serlo la intención del apetito sensitivo puesto que depende de un órgano corporal que puede ser alterado materialmente. De esta manera, la intención requerida para el acto perceptivo puede ser forzada por un agente externo, ya sea un ángel o los objetos externos mismos. No obstante, en este punto parece haber cierta circularidad entre el conocimiento sensitivo y el apetito sensitivo.

De acuerdo a lo dicho podemos decir que la actividad de las potencias cognoscitivas sensitivas depende de la intentio del apetito sensitivo o del apetito intelectual. Pero existe un problema con esta afirmación porque el Aquinate sostiene en varias oportunidades que el apetito sigue al conocimiento en lugar de precederlo. ${ }^{11}$ El apetito sensitivo y el apetito racional no se mueven a menos que lo apetecido sea percibido previamente, pero parecería ser que nada es percibido sin la actividad de alguno de estos dos apetitos. Si percibimos un color, por ejemplo, es porque hay una intentio, pero si un apetito tiende a ese color es porque se lo percibió con anterioridad. Parecería haber un círculo vicioso o una regresión al infinito en la percepción y lo mismo ocurría con el entendimiento.

Praeterea, si voluntas movet intellectum ad suum actum, tunc sequitur quod intellectus intelligat, quia voluntas vult ipsum intelligere. Sed voluntas non vult aliquid nisi intellectum. Ergo prius intellectus intellexit ipsum intelligere quam voluntas illud vellet. Sed antequam intellectus hoc intelligeret, oportet ponere quod voluntas illud vellet, quia ponitur intellectus a voluntate moveri. Ergo est abire in infinitum; vel dicendum, quod voluntas non movet intellectum (De veritate, q. 22, a. 12, arg. 2).

Además, si la voluntad mueve al intelecto a su acto, entonces se sigue que el intelecto entiende porque la voluntad misma quiere entender. Pero la voluntad no quiere algo si no es entendido. Por tanto, el intelecto conoció su propio entender antes que la voluntad

11 Tomás, In Sent. I, d. 1 q. 1 a. 1 ad 1: "appetitus semper sequitur cognitionem"; ST I, q. 81, a. 2, co.: "appetitus sensitivus est inclinatio consequens apprehensionem sensitivam"; De veritate, q. 22, a. 1, co.: "A se quidem in finem dirigi non possunt nisi illa quae finem cognoscunt. Oportet enim dirigens habere notitiam eius in quod dirigit."; In Sent. III, d. 27, q. 1, a. 2, co.: "Intendere autem finem impossibile est, nisi cognoscatur finis sub ratione finis, et proportio eorum quae sunt ad finem in finem ipsum". 
lo quisiera. Pero antes de que el intelecto lo entendiese, es necesario establecer que la voluntad lo quiso, ya que se afirma que el intelecto es movido por la voluntad. Por lo tanto, o hay que ir al infinito o debe decirse que la voluntad no mueve al intelecto (De veritate, q. 22, a. 12, arg. 2).

La respuesta a este problema proviene de parte de un tercer apetito, a saber, el apetito natural. El Aquinate sostiene que toda potencia del alma es una forma y que como tal "tiende" a su objeto propio de manera natural, es decir, toda potencia tiene una intentio naturalis. ${ }^{12}$ No hay una regresión al infinito entre el entendimiento y la voluntad pues "statur enim in appetitu naturali, quo inclinatur intellectus in suum actum" [está establecido en el apetito natural que el intelecto sea inclinado a su acto] (De veritate, q. 22, a. 12, ad 2). Lo mismo ocurre en el caso del sentido y el apetito sensitivo.

Unde patet quod visus appetit naturaliter visibile solum ad suum actum, scilicet ad videndum, animal autem appetit rem visam per vim appetitivam, non solum ad videndum, sed etiam ad alios usus. Si autem non indigeret anima rebus perceptis a sensu, nisi propter actiones sensuum, scilicet ut eas sentiret; non oporteret appetitivum ponere speciale genus inter potentias animae, quia sufficeret appetitus naturalis potentiarum (ST I, q. 78, a. 1, ad 3).

De donde se evidencia que la vista apetece naturalmente el objeto visible solamente en orden a realizar su acto, esto es, para ver, mientras que el animal apetece la cosa vista por la facultad apetitiva no solo para ver, sino también para otros usos. Si el alma no necesitara las cosas percibidas por el sentido sino para ejercitar el sentido, esto es, para sentirlas, no sería necesario poner un apetito especial en el género de las potencias del alma, porque sería suficiente con el apetito natural de las potencias (ST I, q. 78, a. 1, ad 3).

En este pasaje Tomás de Aquino sostiene que por el apetito sensitivo el animal desea el objeto "no solo" (non solum) para mirarlo sino también para utilizarlo, evidenciando de esta manera que dicho apetito cumple alguna función en la percepción. Con todo, luego aclara que el rol que desempeña el apetito sensitivo no debe ser considerado condición necesaria para el acto perceptivo, ya que para percibir "sería suficiente con el apetito natural de las potencias".

Una vez presentado el objeto a la potencia sensitiva, esa potencia se dirigirá de manera necesaria hacia el mismo y lo percibirá debido a la inclinación natural que posee. Por esta razón, el Aquinate llega a decir que "si color proponatur visui, ex necessitate movet visum, nisi aliquis visum avertat" [si se presenta un color a la vista, necesariamente mueve la visión a no ser que alguien desvíe la mirada] (ST I-II, q. 10, a. 2, co.). Ahora bien, si la intentio naturalis de la facultad sensitiva es suficiente para percibir, ¿por qué razón afirma en otros lugares que todo acto cognoscitivo necesita o bien la intentio del apetito sensitivo o bien la intentio del apetito intelectual? La respuesta viene por el lado de la jerarquía que existe entre los distintos apetitos. Con respecto al apetito intelectual debe tenerse en cuenta que tiene potestad sobre todas las demás potencias del alma.

Quaelibet autem potentia comparatur ad aliquod bonum proprium sibi conveniens; sicut visus ad perceptionem coloris, intellectus ad cognitionem veri. Et ideo voluntas per modum agentis movet omnes animae potentias ad suos actus, praeter vires naturales vegetativae partis, quae nostro arbitrio non subduntur (ST I, q. 82, a. 4, co.).

Toda potencia se dispone a algún bien particular que le es conveniente, como la vista a la percepción del color, y el intelecto al conocimiento de la verdad. Por este motivo la

12 Tomás, ST I, q. 80, a. 1, ad 3: "unaquaeque potentia animae est quaedam forma seu natura, et habet naturalem inclinationem in aliquid". 
voluntad mueve a todas las potencias del alma a sus actos por el modo del agente, excepto las potencias naturales de la parte vegetativa que no están sometidas a nuestro arbitrio (ST I, q. 82, a. 4, co.).

El color mueve a la potencia visiva de manera necesaria para percibir, pero el ser humano puede deliberadamente dirigirse o atender a otra cosa y por eso Tomás aclara que el color mueve de manera necesaria a la vista "nisi aliquis visum avertat". Es por este motivo que todo conocimiento, incluyendo la percepción, requiere de la intentio de la voluntad. Para el Aquinate "voluntas a nullo obiecto ex necessitate movetur, potest enim aliquis de quocumque obiecto non cogitare" [la voluntad no es movida por ningún objeto de manera necesaria, ya que alguien puede no pensar en ningún objeto] (ST I-II, q. 10, a. 2, co.) o puede dirigir su atención a otro objeto en detrimento del primero. La sola aparición del color en el campo visual no asegura su conocimiento si la intentio de la voluntad se orienta hacia otra cosa.

Por otra parte, se debe tener en cuenta que los animales no poseen un apetito intelectual pero sí un apetito sensitivo que es superior al apetito natural de las potencias del alma. Es fácil imaginar a un perro que no ve a los transeúntes porque atiende a la comida que tiene en frente. En este caso la intención del apetito sensitivo es tan fuerte que impide la acción de la vista, puesto que "necesse est quod quando una potentia intenditur in suo actu, altera in suo actu remittatur, vel etiam totaliter impediatur" [es necesario que cuando una potencia tiende a su acto, la otra afloje en su acto, o también este totalmente impedida] (ST I-II, q. 77, a. 1, co.).

Algo semejante ocurre en el caso del ser humano. Quedó establecido que toda potencia cognoscitiva tiende de manera natural a su objeto, pero de todas maneras se necesita de la intención de la voluntad para percibir. Esto se debe a que el sujeto puede decidir no atender al objeto que inmuta la potencia y así no habrá conocimiento. Esta es la razón por la cual Tomás de Aquino apela a la intención del apetito sensitivo para explicar la influencia de los ángeles en las facultades cognoscitivas del ser humano.

Si los ángeles no pueden mover la intención de la voluntad, la única alternativa que tienen para hacer que una persona sienta o imagine algo radica en la intención del apetito sensitivo. Este apetito posee un órgano corpóreo sobre el cual el ángel puede actuar, de hecho, es posible que una intención vehemente del apetito sensitivo anule la intención de la voluntad.

Tum quia in operibus animae requiritur quaedam intentio, quae dum vehementer applicatur ad unum, non potest alteri vehementer attendere. Et secundum hunc modum, per quandam distractionem, quando motus appetitus sensitivi fortificatur secundum quamcumque passionem, necesse est quod remittatur, vel totaliter impediatur motus proprius appetitus rationalis, qui est voluntas (ST I-II, q. 77, a. 1, co.).

Luego, debido a que se requiere alguna intención en las operaciones del alma, mientras se aplica de manera vehemente a uno, no puede atender de manera vehemente a otro. Y según este modo, por alguna distracción, cuando el movimiento del apetito sensitivo se fortalece de acuerdo a alguna pasión, es necesario que afloje o esté totalmente impedido el movimiento propio del apetito racional, que es la voluntad (ST I-II, q. 77, a. 1, co.).

De esta manera observamos que en la percepción están involucrados los tres apetitos. El apetito natural de la potencia cognoscitiva es suficiente para que el animal perciba, de esta manera la inmutación por parte del color mueve necesariamente a la vista. Pero esta percepción podría no darse si la intención del apetito sensitivo es vehemente, como el ejemplo del perro que atiende de manera vehemente a la comida 
y no ve a los transeúntes. Lo mismo ocurre en el caso del ser humano cuando esta vehemencia anula el acto de la voluntad y así es como para Tomás de Aquino los ángeles pueden actuar sobre las potencias cognoscitivas del ser humano. Por último, sobre estos dos apetitos se encuentra la voluntad que puede actuar sobre todas las potencias cognoscitivas e incluso sobre los otros apetitos.

De esta manera se resuelve el problema de la suficiencia de los objetos sensibles para causar el acto perceptivo. La intención necesaria para percibir está asegurada por el apetito natural que poseen las facultades sensitivas y de esta forma cuando los objetos externos inmutan algún órgano sensorio se produce la percepción. Por otra parte, el Aquinate afirma que la intención de la voluntad es necesaria porque si esta intentio se orienta a otra cosa, puede impedir la percepción. Esto es así porque no se puede atender a más de una cosa a la vez.

\section{Conclusión}

Comenzamos este trabajo señalando que una teoría intencionalista de la percepción podría resultar implausible porque parece atentar contra la pasividad de las facultades sensitivas y la suficiencia del objeto sensible para causar la percepción. Sin embargo, cuando uno se adentra en la teoría del conocimiento sensitivo del Aquinate se puede observar que en realidad dicha teoría no es problemática. Los objetos sensibles son causa suficiente de la percepción ya que su sola presencia hace que las facultades tiendan hacia ellos. Esto se debe a que cada facultad tiene un apetito natural por el cual se dirige a su objeto propio.

Aunque el objeto sea causa suficiente de la percepción, la intentio de la voluntad es necesaria en algún sentido. En efecto, si por algún motivo el ente cognoscitivo dirige su atención a otra cosa que no sea el objeto que se encuentra en el campo perceptivo, no habrá conocimiento del mismo. Esto se debe a que no se puede atender a más de una cosa a la vez y cuando las diferentes intenciones entran en conflicto, la intentio que pertenece a la voluntad es la que generalmente prevalece ya que gobierna sobre todas las demás potencias.

Por otra parte, hemos probado que para Tomás de Aquino la intencionalidad del conocimiento es obra de algún apetito. La intencionalidad puede venir del apetito natural de la facultad misma o de una potencia apetitiva, sea racional o sensitiva. Además, se ha demostrado que la presencia de alguno de estos apetitos es necesaria para el acto cognoscitivo. En el conocimiento intelectual la intervención de la voluntad asegura que ningún ente creado pueda conocer directamente lo que otro ente cognoscitivo está pensando. En cuanto a los sentidos, la presencia de alguno de los apetitos garantiza su pasividad puesto que los mismos se dirigen a los objetos en cuanto que son movidos por la voluntad o el apetito sensitivo. 


\section{Bibliografía}

\section{Fuentes}

\section{Ediciones}

» Thomas Aquinas (1856). Commentum in quartum librum Sententiarum magistri Petri Lombardi (Opera omnia 7/2). Ed. Typis Petri Fiaccadori: Parma.

" Thomas Aquinas (1982). Quaestiones disputatae de malo (Opera omnia 23). Ed. Leonina: Roma.

" Thomas Aquinas (1996). Quaestiones de Quodlibet. Quodlibet VII, VIII, IX, X, XI. Ed. Leonina: Roma.

\section{Traducciones}

" Agustín de Hipona (1967). Tratado sobre la Santísima Trinidad. Trad. Arias, L. Madrid: BAC.

" Aristóteles (1978). Acerca del alma. Trad. Calvo, T. Madrid: Gredos.

" Tomás de Aquino (1947). Suma Teológica I. Madrid: BAC.

» Tomás de Aquino (1952). Suma Contra los Gentiles. Madrid: Editorial Católica.

» Tomás de Aquino (1954-1959). Suma Teológica III-VI. Madrid: BAC.

» Tomás de Aquino (1999). De veritate. Cuestión 13: Tratado sobre el arrebato místico. Trad. Tellez, E. Pamplona: Servicio de Publicaciones de la Universidad de Navarra.

» Tomás de Aquino (2001). De veritate. Cuestión 10: La mente. Trad. González, A. Pamplona: Servicio de Publicaciones de la Universidad de Navarra.

» Tomás de Aquino (2001). De veritate. Cuestión 12: Sobre la profecía. Trad. Tellez, E. Pamplona: Servicio de Publicaciones de la Universidad de Navarra.

"Tomás de Aquino (2001). De veritate. Cuestión 22: El apetito del bien. Trad. Sellés, J. Pamplona: Servicio de Publicaciones de la Universidad de Navarra.

"Tomás de Aquino (2001). El Maestro: Cuestiones disputadas sobre la Verdad, c. 11. Suma Teológica 1, c. 117. Trad. Muñoz, P. Lima: Fondo Editorial UCSS.

"Tomás de Aquino (2003). De veritate. Cuestión 8: El conocimiento de los Ángeles. Trad. González, A. y Sellés, J. Pamplona: Servicio de Publicaciones de la Universidad de Navarra.

\section{Bibliografía}

» Beuchot, M. (2008). Conocimiento, realidad y acción en santo Tomas de Aquino. Salamanca: Editorial San Esteban.

" Brower, J. y Brower-Toland, S. (2008). "Aquinas on Mental Representation: Concepts and Intentionality", The Philosophical Review 117, 193-243. 
» Carcedo, L. (1992). Tomás de Aquino. Salamanca: Ediciones Universidad de Salamanca.

" Caston, V. (2005). "The Spirit and the Letter: Aristotle on Perception". En: Salles, R. (ed.). Metaphysics, Soul and Ethics in Ancient Thought. Themes From the Work of Richard Sorabji. Oxford: Oxford University Press, 245-320.

"Davies, B. (1992). The Thought of Thomas Aquinas. Oxford: Clarendon Press.

» Dewan, L. (1980). "St. Albert, the Sensible, and Spiritual Being". En: Weisheipl, J. A. (ed.). Albertus Magnus and the Sciences. Commemorative Essays. Toronto: PIMS, 291-320.

"Geach, P. (1954). "Form and Existence", Proceedings of the Aristotelian Society 55, 251-272.

»González Vidal, N. (2008). La pasión de la tristeza y su relación con la moralidad en santo Tomás de Aquino. Pamplona: Servicio de Publicaciones de la Universidad de Navarra. (Cuadernos de Anuario Filosófico 205).

» Haldane, J. (1989). "Brentano's Problem”, Grazer Philosophische Studien 35, 1-32.

"Haldane, J. (1993). "Mind-World Identity Theory and the Anti-Realist Challenge". En: Idem y Wright, C. (eds.). Reality, Representation and Projection, 15-37.

» Klima, G. (2013). "Three Myths of Intentionality Versus Some Medieval Philosophers", International Journal of Philosophical Studies 21.3, 359-376. DOI: 10.1080/09672559.2013.788266.

»Lane, M. (2013). The Role of intentio in Augustine's Understanding of the Soul's Ascent to God: From De animae quantitate to De trinitate. Durham: Durham University. (Durham theses. Disponible en: http://etheses.dur.ac.uk/10571/).

» Moser, R. (2009). St. Thomas Aquinas and John Haldane on Knowledge of Material Things (tesis doctoral). Ottawa: Universidad de Ottawa.

" Moya Cañas, P. (1999). "Dificultades que surgen en la comprensión del conocimiento sensible", Tópicos. Revista de Filosofía 16.1, 87-123.

» Panaccio, C. (1997). "Angel's Talk, Mental Language, and the Transparency of the Mind". En: Marmo, C. (ed.). Vestigia, Imagines, Verba. Semiotics and Logic in Medieval Theological Texts (XIIth-XIVth Century). Turnhout: Brepols, 323-335.

" Pasnau, R. (1997). Theories of Cognition in the Later Middle Ages. Cambridge: Cambridge University Press.

» Perler, D. (2004). Theorien der Intentionalität im Mittelalter. Frankfurt: Klostermann.

»Sanguinetti, J. J. (2011). "La especie cognitiva en Tomás de Aquino", Tópicos. Revista de Filosofía 40, 63-103.

"Scarpelli Cory, T. (2015). "Attention, Intentionality, and Mind-Reading in Aquinas's De Malo 16.8". En: Dougherty, M. V. (ed.). Aquinas's Disputed Questions on Evil. Cambridge: Cambridge University Press, 164-191.

"Sorabji, R. (1991). "From Aristotle to Brentano. The Development of the Concept of Intentionality". En: Blumenthal, H. y Robinson, H. (eds.). Festschrift fur A. C. Loyd: on the Aristotelian Tradition. Oxford: Oxford University Press, 227-259. 